\title{
Pelatihan Uji Sentuh Jari Kaki Sebagai Upaya Peningkatan Ketrampilan Kader Kesehatan Dalam Mendeteksi Gangguan Sensasi Kaki
}

\author{
Suyanto $^{1 *}$ Sri Lestari Dwi Astuti² \\ 1,2 Jurusan Keperawatan, Politeknik Kesehatan Surakarta \\ *Email: suyanto.mkes@gmail.com
}

\begin{abstract}
Background: Increased life expectancy will be followed by increasing problems if health care is not carried out properly. Problems will arise, one of which is endocrine system disorders such as diabetes mellitus which has complications. One of the complications of diabetes mellitus is diabetic ulcers on the feet by $7.5 \%$ of patients who experience impaired sensation which ultimately have to undergo amputation. This condition can be prevented early, such as by checking the sensation of the feet. This activity aims to increase the role of health cadres in detecting the incidence of neuropathy. Methods: In order to provide knowledge and skills of the toe touch test to 30 health cadres, the method chosen was training supported by guidebooks, videos and demonstrations. Results: There was an increase in the knowledge of cadres in good categories from $13 \%$ to $89 \%$ between before and after training. Meanwhile, the skills of the cadres showed that all of the training participants were skilled in doing the toe touch test. Conclusion: Improving the knowledge and skills of cadres can be pursued through training by combining the use of manuals, videos and demonstrations.
\end{abstract}

Keywords: detection, foot sensation, health cadres

\section{PENDAHULUAN}

Usia harapan hidup masyarakat di Indonesia saat ini 66,2 tahun dengan populasi yang disebut lansia sebesar 20 juta jiwa $(9,51 \%)$ dan akan terus meningkat usia harapan hidup tersebut menjadi 67,4 tahun pada tahun 2020 dengan perkiraan populasi lansia sebesar 28,8 juta jiwa (11,34\%) (Kemenkes.R.I, 2018). Bertambahnya usia harapan hidup akan diikuti dengan semakin bertambah populasinya. Hal ini menjadi masalah tersendiri karena akan bermunculan berbagai masalah khususnya masalah gangguan kesehatan seperti gangguan sistem endokrin dan metabolisme yang dapat muncul berupa penyakit Diabetes Melitus (DM).

Bila penyakit DM tidak ditangani dengan baik akan menimbulkan komplikasi kronis baik angiopati maupun neuropati. Salah satu komplikasinya adalah luka kaki diabetes (Price, S. A., \& Wilson, 2009). Neuropati dapat dideteksi dengan menggunakan monofilament test, sedangkan angiopati dideteksi melalui pemeriksaan ABI (Ankle Brachial Index). Akan tetapi kedua alat ini belum tentu tersedia di unit pelayanan kesehatan dan harus dilakukan oleh tenaga profesional (Baraz et al, 2014).

Saat ini telah dibuat sebuah cara menguji sensifitas kaki untuk mendeteksi neuropati pada pasien DM yang dilakukan dengan cara sederhana tanpa menggunakan alat khusus untuk menjawab permasalahan di atas. Instrumen tersebut dinamakan IPWICH Touch Test atau disingkat IpTT (Safitri, 2015). Menurut penelitian, tes sederhana ini dapat digunakan oleh tenaga non-profesional untuk menilai secara akurat hilangnya sensasi dengan instruksi tertulis. Instrumen ini dapat berguna untuk meningkatkan kesadaran pada pasien tentang komplikas luka kaki diabetes dan memberdayakan orang disekitar pasien. Sehingga bila di masyarakat dijumpai kondisi neuropati maka dapat segera mencari pelayanan perawatan yang tepat dengan cepat 
(Sharma et al, 2014).

Berdasarkan Profil Kesehatan Kabupaten Karang Anyar tahun 2019 terdapat 11.841 penduduk yang menderita diabetes mellitus. Sebanyak 545 orang diantaranya ditemukan di wilayah kerja puskesmas Matesih. Terjadi kenaikan jumlah penderita bila dibandingkan beberapa tahun sebelumnya seperti terlihat pada tahun 2014 diketahui jumlah penderita 64 orang dan pada tahun 2017 dijumpai menjadi sebanyak 300 orang (Dinas Kesehatan Kab Karanganyar, 2019). Permasalahan komplikasi terbanyak penyakit ini dimulai dari adanya penurunan sensasi kaki kemudian terjadi luka kaki diabetik yang sering berujung dilakukan amputasi. Untuk itu diperlukan adanya tindakan pencegahan dengan pengetahuan dan ketrampilan memeriksa sensasi kaki yang dapat dilakukan secara mandiri.

Penelitian yang melatih tenaga non profesional yaitu kader kesehatan tentang ketrampilan memeriksa sensasi kaki dengan bantuan buku panduan uji sentuh jari kaki menunjukkan bahwa kader kesehatan diketahui mampu melakukan pemeriksaan deteksi sensasi kaki. Penelitian ini dilakukan dengan metode kader kesehatan terlebih dahulu diberi penjelasan. Lalu demonstrasi dan latihan serta bilamana perlu dilanjutkan pendampingan pada kader untuk melatih ketrampilannya (Suyanto; Sri Lestari DA, 2020). Dengan demikian upaya mencegah penyakit ini perlu segera dilakukan mengingat jumlah penderita yang menjadi semakin banyak. Lebih khusus tindakan pencegahan penyakit jangan berlanjut sehingga komplikasi bahkan amputasi dapat dicegah.

Untuk itu kiranya segera dilakukan peningkatkan kapasitas kader kesehatan sebagai tenaga non profesional dan sumber daya yang ada di desa agar dapat ikut berperan mencegah komplikasi penderita dapat menjadi suatu pilihan kegiatan. Berdasarkan kondisi tersebut maka dosen Jurusan Keperawatan Poltekes Surakart yang memiliki pengetahuan dan ketrampilan dalam mencegah komplikasi pada penyakit Diabetes Melitus serta memiliki kewajiban melaksanakan Tri Dharma Perguruan Tinggi telah melakukan kegiatan pengabdian masyarakat dalam bentuk Peningkatan Kapasitas Kader Kesehatan dalam Deteksi Gangguan Sensasi Kaki Penderita Diabetes Melitus di Desa Ploso Rejo Kec Matesih Kabupaten Karang Anyar Jawa Tengah.

\section{TINJAUAN PUSTAKA}

Berbagai bentuk tes atau pemeriksaan dapat dilakukan untuk memeriksa adanya neuropati yaitu dengan melakukan uji sensitiftas seperti monofilamen test dan vibarasi tes. Kedua tes tersebut memerlukan ketrampilan dan alat khusus yang tidak semua unit pelayanan kesehatan memilikinya (Baraz et al, 2014). Saat ini telah ditemukan IPWICH Touch Test yang selanjutnya di singkat menjadi IpTT yang merupakan tes sederhana. Dijelaskan bahwa IpTT adalah screening yang dirancang untuk memprediksi resiko ulkus. Tes ini mudah dan sederhana untuk diajarkan baik untuk kalangan profesional maupun non profesioanl (Sharma et al, 2014).

Tes ini berlangsung dalam waktu singkat (1-2 detik) dengan menyentuh ujung pertama, ketiga, dan kelima jari-jari kedua kaki dengan jari telunjuk untuk mendeteksi adanya hilangnya sensasi. Pemeriksaan IpTT dilakukan dengan menyentuhkan (tanpa tekanan) ujung jari pemeriksa pada ujung jari (Rayman et al., 2011). IpTT adalah metode baru untuk mendeteksi penderita Diabetes Melitus yang kehilangan sensasi kaki dengan cara sederhana, aman, cepat, dan mudah dilakukan dan diajarkan. Tes ini dilakukan dengan ringan sekitar 1-2 detik dengan menyentuh ibu jari kaki kanan, jari kelingking kanan, ibu jari kaki kiri, jari kelingking kiri, jari tengah kaki kanan, jari 
tengan kaki.
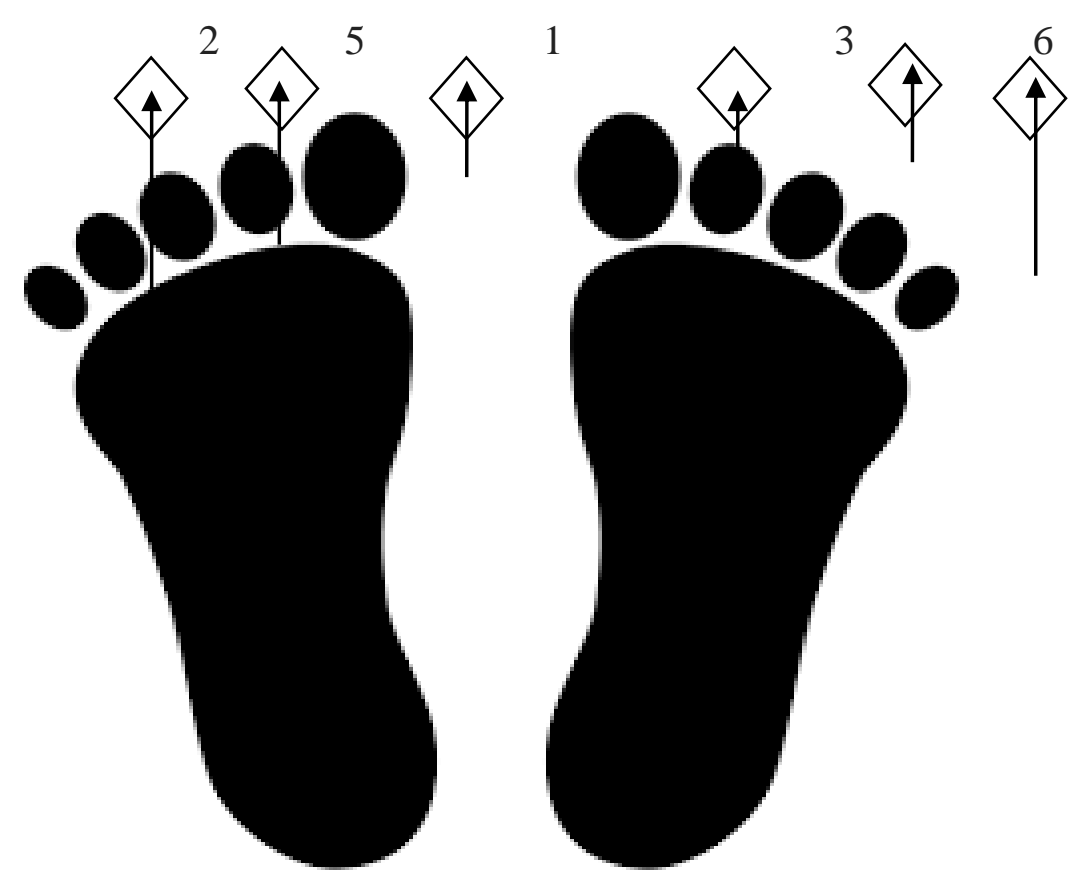

KANAN KIRI

Gambar 1. Sensasi Kaki Kanan dan Kiri

Dikatakan sensasi kaki normal jika penderita merasakan sentuhan pada 6 atau 5 dari jari yang disentuh. Hal ini berarti tidak beresiko mengalami masalah sensasi kaki. Namun, harus terus memeriksa setiap saat bila diperlukan. Dikatakan mengalami gangguan sensasi jika: Dari 6 jari yang disentuh Ada 2 jari atau lebih tidak merasa sentuhan. Berarti mengalami penurunan sensasi dan berisiko terkena ulkus kaki diabetik. Jika terjadi maka perlu dilakukan pengujian lebih lanjut di rumah sakit atau klinik oleh perawat atau dokter.

\section{DESAIN PENELITIAN}

Sesuai dengan permasalahan, maka pengabdian masyarakat yang dilaksanakan mulai bulan Maret 2021 hingga bulan Juli 2021 dalam bentuk pelatihan pemeriksaan sensasi kaki dengan metode uji sentuh jari kaki. Pelaksanaanya dilakukan dengan berbagai bentuk mengingat bahwa saat ini masih berlangsung pandemi Covid 19. Teknis kegiatan dilakukan dengan membagi peserta menjadi 5 kelompok kecil masing masing kelompok terdiri 6 kader dan tidak melakukan pertemuan langsung kecuali pada saat evaluasi.

Adapun rincian kegiatan sebagai berikut: Pada tanggal 5 sampai dengan 7 April 2021 dilakukan pre test untuk memperoleh tingkat pengetahuan kader tentang uji sentuh jari kaki menggunakan lembar kuesioner yang dikembangkan dari buku Touch The Toes dengan nilai $p$ value 0,000<0,005 (Suyanto; Sri Lestari DA, 2020). Kuesioner pre test tersebut dibagikan oleh ketua kelompok kecil ke kediaman masing masing kader. Kemudian pada tanggal 19 sampai dengan 22 April dibagikan buku panduan uji sentuh jari untuk dipelajari kader oleh ketua kelompok kecil ke rumah masing masing kader. Pada saat itu juga dibagikan video yang berisi demonstrasi cara melakukan uji sentuh jari kaki melalui whatsapp group kader. 
Selanjutnya pada tanggal 8 Juni 2021 dilakukan post test untuk mengetahui tingkat pengetahuan kader tentang uji sentuh jari kaki yang pelaksanaanya dilakukan di Balai Desa Ploso Rejo Kecamatan Matesih Kabupaten Karanganyar dengan menerapkan protokol kesehatan Covid 19 yaitu memakai masker yang dibagikan penulis, menggunakan hand sanitizer dan menjaga jarak dalam kelompok kecil masing masing. Kegiatan berikutnya yaitu melakukan evaluasi dalam bentuk demonstrasi oleh setiap kader dalam kelompok kecil masing masing. Demonstrasi dalam kelompok kecil di observasi oleh penulis yang dibantu oleh 3 orang mahasiswa Jurusan keperawatan Poltekkes Surakarta.

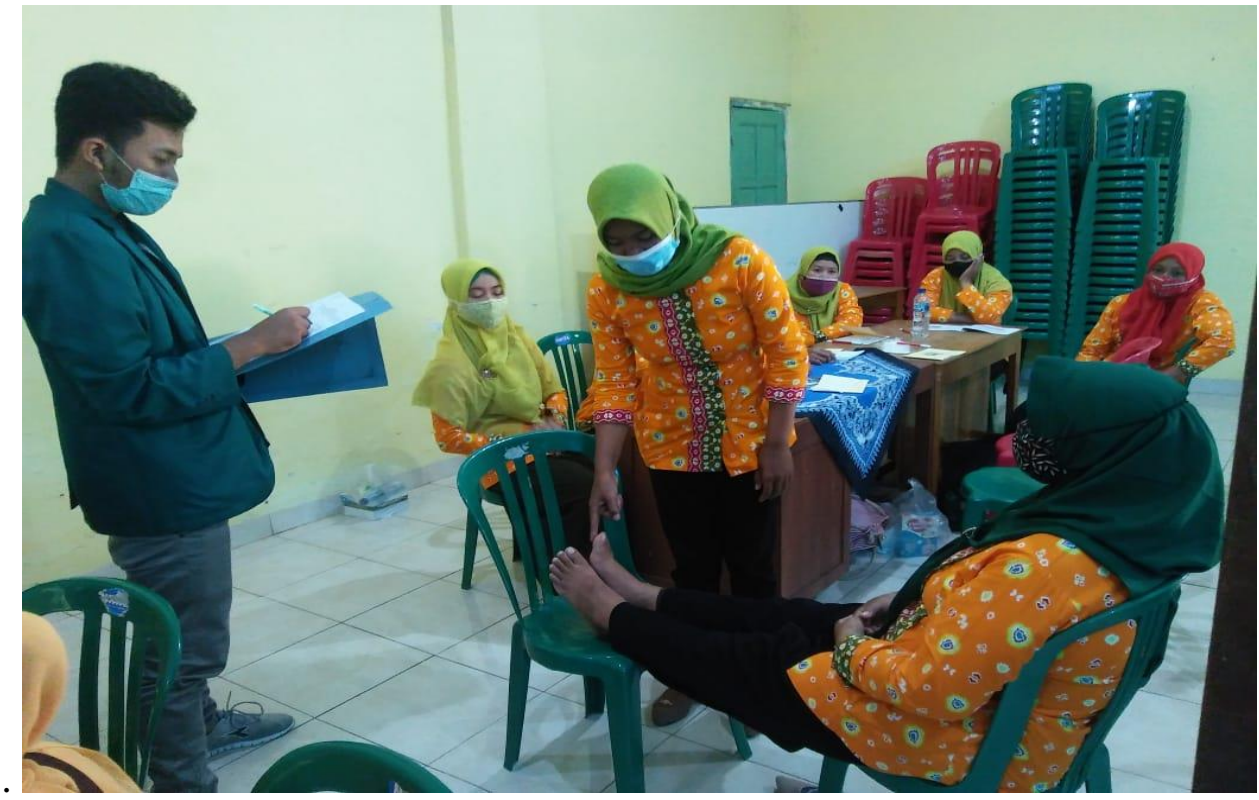

Gambar 2. Evaluasi Ketrampilan Uji Sentuh Jari Kaki Oleh Mahasiswa

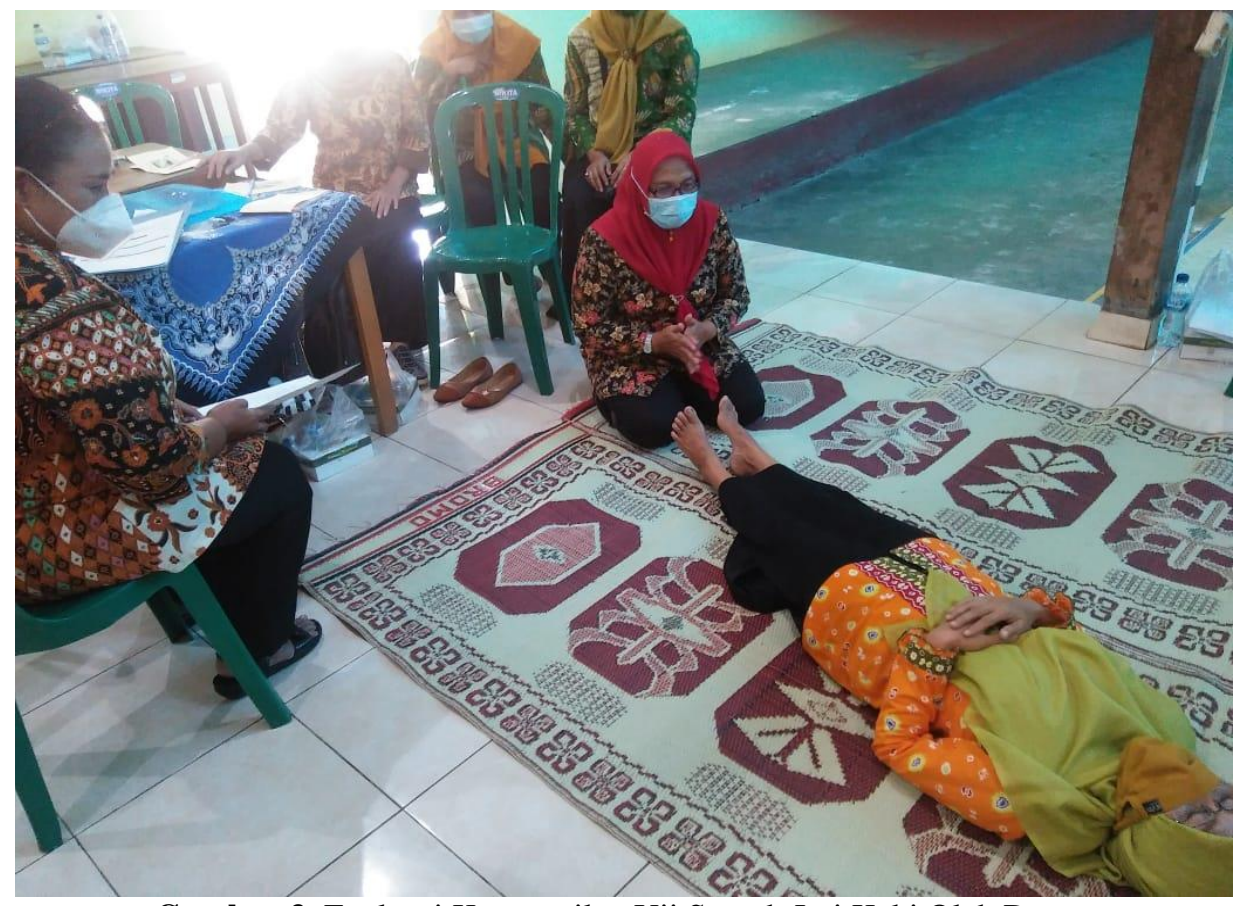

Gambar 3. Evaluasi Ketrampilan Uji Sentuh Jari Kaki Oleh Dosen 


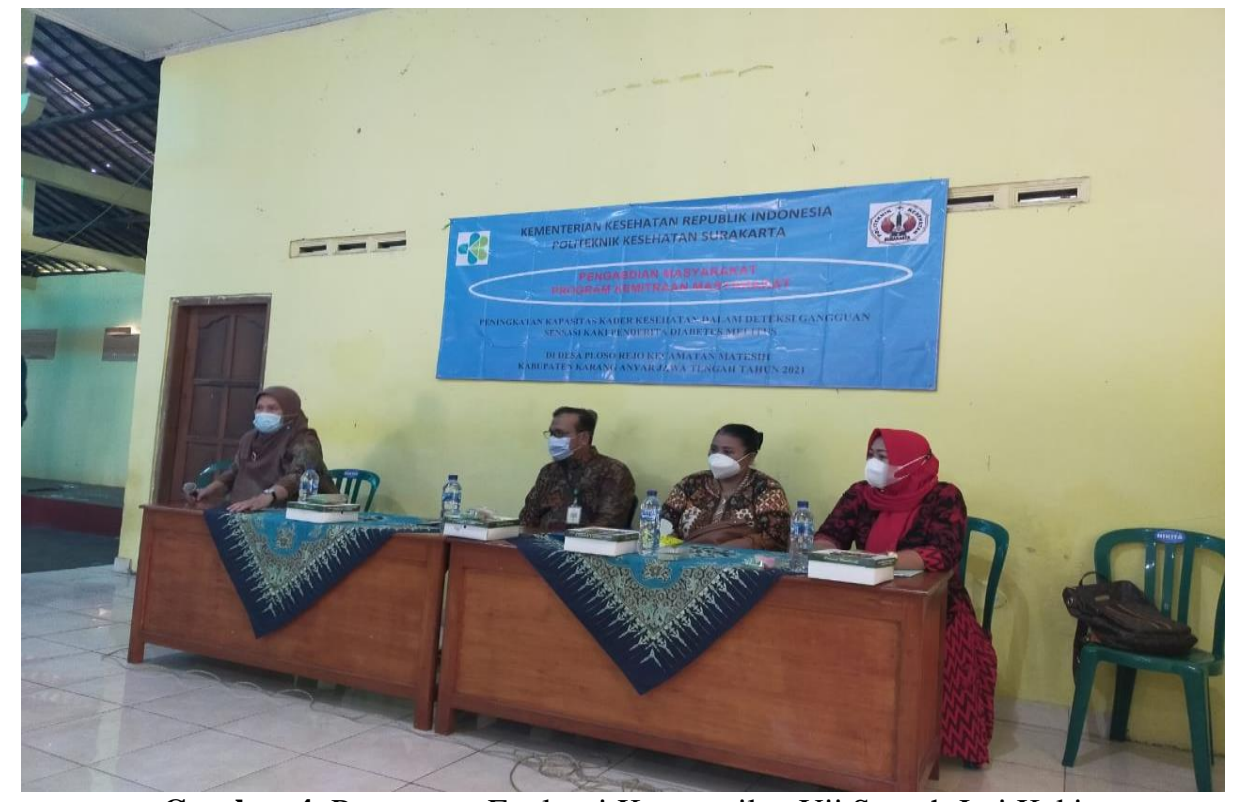

Gambar 4. Pertemuan Evaluasi Ketrampilan Uji Sentuh Jari Kaki

\section{HASIL PENELITIAN}

Kegiatan pengabdian masyarakat Program Kemitraan Masyarakat yang telah dilaksanakan dalam bentuk pelatihan kader menghasilkan berapa hal yang dapat dijadikan sebagai bahan pertimbangan kegiatan berikutnya sebagaimana dapat dilihat pada table beikut ini:

Tabel. Pengetahuan Kader Kesehatan Tentang Pemeriksaan Uji Sentuh Jari Sebelum dan Sesudah Pelatihan

\begin{tabular}{lcccc}
\hline \multirow{2}{*}{ Pengetahuan Kader } & \multicolumn{2}{c}{ Sebelum } & \multicolumn{2}{c}{ Sesudah } \\
\cline { 2 - 5 } & f & \% & f & \% \\
\hline Baik & 3 & 11 & 27 & 89 \\
Sedang & 7 & 22 & 3 & 11 \\
Kurang & 20 & 67 & 0 & 0 \\
\hline Total & 30 & 100 & 30 & 100 \\
\hline
\end{tabular}

Pada table terlihat bahwa tingkat pengetahuan kader yang diukur sebelum pelatihan menggunakan kuesioner pre test sebagian besar buruk. Hal tersebut bebeda setelah dilakukan pemberian buku panduan uji sentuh jari kaki dan video yang berisi tata cara melakukan uji sentuh jari kaki. Tingkat pengetahuan kader berubah ditemukan lagi kader berpengatahuan kurang.

Kemudian dilakukan penilaian ketrampilan setelah sebelumnya para kader kesehatan diberi kesempatan mempelajari buku panduan pemeriksaan uji sentuh jari dan menyaksikan video tata cara melakukan uji sentuh jari yang telah dibagikan melalui Whatsapp Group kader . Adapun hasil penilaian ketrampilan yang diperoleh yaitu pada umumnya kader dapat melakukan pemeriksaan uji sentuh jari kaki yang diobservasi oleh dosen dan mahasiswa dalam kelompok kecil. Terdapat 3 orang kader yang masih belum terampil melakukan pemeriksaan. Mereka melakukan kesalahan pada aspek urutan jari yang disentuh dan kelembutan sentuhan. Tetapi setelah diberikan bimbingan oleh observer mereka dapat melakukannya dengan benar. 


\section{PEMBAHASAN}

Perubahan pengetahuan kader tentang cara melakukan pemeriksaan uji sentuh jari yang menjadi lebih baik dapat dijelaskan sebagai hasil dari metode pendidikan yang digunakan. Metode dengan cara memberikan buku panduan menjadi faktor utama terjadinya perubahan tersebut sebagamana penelitian tentang peningkatan pengetahuan kader tentang deteksi dini diabetic foot dapat dilakukan dengan pelatihan (Herlina, Santii. Ladesvita \& Florensia, 2019). Hal tersebut juga didukung oleh penjelasan bahwa uji sentuh adalah buah metode sederhana untuk skrining diabetic foot ulcer (Safitri, 2015) dan (Kusumaningrum, 2015). Sehingga metode yang sederhana ini membuat merekomendasikan uji sentuh jari kaki dapat diajarkan pada masyarakat non profesioanal kesehatan (Rayman et al., 2011).

Kemampuan ketrampilan pemeriksaan uji sentuh jari yang dimiliki oleh seluruh kader yang dinilai baik juga berkaitan dengan kesederhanaan cara pemeriksaan uji sentuh jari. Sehingga ketrampilan ini bisa dilatih menggunakan media buku panduan dan menyaksikan video. Hal ini mendukung temuan bahwa ketrampilan kader dapat dilatih menggunakan berbagai media (Sulistiyawati, 2019). Dengan demikiam maka kader sebagai tenaga non profesional kesehatan selayaknya dilatih agar dap meningkat kemampuannyz sehingga kondisi masyarakat yang banyak menderita diabetes dapat dipantau dengan baik. Bahkan bilamana memungkinkan dapat di latih pada penderita diabetes itu sendiri dengan menggunakan paket edukasi dan deteksi dini diabetic foot (Nuniek. et al, 2020).

\section{KESIMPULAN DAN SARAN}

Mengingat kesederhanaan tata cara pemeriksaan uji sentuh jari kaki dibanding manfaatnya maka, deteksi dini neuropati menggunakan uji sentuh jari kaki dapat diajarkan pada tenaga non profesional seperti kader kesehatan sebab cara melakukanya mudah dan tanpa alat. Agar pengetahuan dan ketrampilan yang diajarkan dapat maksimal diperlukan buku panduan cara melakukan uji sentuh jari kaki dan pelatih melakukan pendampingan hingga kader kesehatan terampil.

Ketrampilan deteksi neuropati menggunakan uji sentuh jari kaki yang telah dimiliki kader harus sering dilakukan seperti di Posyandu Lansia untuk melatih kemampuan kader kesehatan. Selain itu bertujuan untuk menigkatkan upaya pencegahan neuropati di masyarakat dengan deteksi sedini mungkin menggunakan uji sentuh jari kaki.

\section{DAFTAR RUJUKAN}

Baraz et al. (2014). Comparison of the accuracy of monofilament testing at various points of feet in peripheral diabetic neuropathy screening. Journal of Diabetes \& Metabolic Disorders, 13.

Dinas Kesehatan Kab Karanganyar. (2019). Profil Kesehatan Kab. Karanganyar. Retrieved fromhttp://www.mediafire.com/file/87gmkcnxq4pxep6/PROFIL_KESEHATAN_ KAB.KARANGANYAR_2019.pdf/file

Herlina, Santii. Ladesvita, F., \& Florensia, L. (2019). Meningkatkan Pegetahuan dan Kemampuan Kader kesehatan melalui pelatihan Deteksi Dini Risiko Diabetik Foot Ulcer. $\quad$ SABDAMAS, Retrieved from 
http://ejournal.atmajaya.ac.id/index.php/sabdamas/article/view/1046

Kemenkes.R.I. (2018). Laporan Nasional Riskesdas 2018. Retrieved from https://dinkes.kalbarprov.go.id/wp-content/uploads/2019/03/Laporan-Riskesdas2018-Nasional.pdf

Kusumaningrum, N. S. D. (2015). Ipswich Touch Test Sebagai Metode Sederhana Untuk Skrining Diabetic Foot Ulcer: In 3rd Adult Nursing in Practice: Using Evidence in Care "Holistic Nursing in Emergency and Disaster: Issue and Future," $61 . \quad$ Retrieved from http://eprints.undip.ac.id/46655/1/Proceeding_Semilnaskes_2015_Niken_Oral_.p df

Nuniek. et al. (2020). Paket Edukasi dan Deteksi Dini Meningkatkan Perilaku Perawatan Kaki Diabetisi di Puskesmas Kabupaten Pekalongan. Jurnal Aiska.Gaster, 18, 19-20. Retrieved from https://jurnal.aiskauniversity.ac.id/index.php/gaster/article/view/402/243

Price, S. A., \& Wilson, L. M. (2009). Patofisiologi Konsep Klinis Proses Proses Penyakit (6th ed.). Jakarta: EGC.

Rayman, G., Vas, P. R., Baker, N., Taylor, Gooday, C., Alder, A. I., \& Donohoe, M. (2011). The Ipswich Touch Test. Diabetes Care. https://doi.org/10.2337/dc110156

Safitri, N. (2015). Ipswich Touch Test sebagai Metode Sederhana untuk Skrining Diabetic Foot Ulcer. Proceeding Seminar Ilmiah Nasional Keperawatan 2015.

Sharma et al. (2014). The Ipswich Touch Test: A simple and novel method to screen patients with diabetes at home for increased risk of foot ulceration. Diabetic Medicine. https://doi.org/10.1111/dme.12450

Sulistiyawati, I. G. P. (2019). Pengaruh Pelatihan Terhadap Keterampilan Kader Posyandu Dalam Pencatatan Kms Balita. Jurnal Akademi Kebidanan Jember, 3, $1-8$.

Suyanto; Sri Lestari DA. (2020). (2020) Efektifitas buku panduan uji sentuh ipswich dalam meningkatkan keterampilan kader kesehatan . Jurnal Kesehatan Holistik, 14. 